\title{
Antrum Approach Planning for Removal of Impacted Tooth Using Cone-Beam Computed Tomography
}

\author{
Allex Morelli Heiderich de Mattos ${ }^{1}{ }^{*}$, Christiano Sampaio Queiroz ${ }^{1}$, Pablo Leal Teixeira Santos ${ }^{1}$, \\ Adriana Borges de Oliviera ${ }^{1}$, Camila Oliveira ${ }^{1}$ and Paulo Sérgio Flores Campos ${ }^{4}$ \\ ${ }^{1}$ School of Dentistry, Federal University of Bahia, Salvador, BA, Brazil \\ ${ }^{4}$ Department of Propedeutics and Integrated Clinic, School of Dentistry, Federal University of Bahia, BA, Brazil
}

\begin{abstract}
Due to the great number of structures in the maxillofacial region, cone-beam computed tomography (CBCT) is an important procedure in presurgical planning for removal of impacted teeth. Most of the information provided by this imaging technique cannot be visualized in conventional radiographs. In addition, CBCT reduces patient exposure to radiation in comparison with helical computed tomography and provides dental practitioners with easy access. We report the clinical case of a patient who underwent a surgical procedure for removal of an impacted maxillary premolar. CBCT-assisted presurgical treatment was used, enabling a more conservative surgical access, a less traumatic and less time consuming procedure than conventional surgical intervention.
\end{abstract}

Keywords: Cone-beam computed tomography, impacted teeth, surgical planning, imaging diagnosis.

\section{INTRODUCTION}

The removal of impacted teeth is one of the most common surgical procedures performed by the oral and maxillofacial surgeon. Impacted maxillary teeth can cause many problems, such as infections, root resorption of adjacent teeth, formation of cysts and tumors, among others [1].

Appropriate imaging examinations are needed in planning removal of an impacted tooth. Lima et al. (2009) stress the importance of proper radiographic examinations in the diagnosis and surgical planning of impacted teeth, since the morphological changes associated with these teeth and their relationship to adjacent structures can be visualized. The radiographic techniques most frequently requested for treatment planning of this type of surgery are periapical, occlusal and panoramic radiographs. However, the imaging obtained may not allow visualization of all the structures in the region in three-dimensions, especially due to overlapping of the anatomical structures. The location of an impacted tooth often requires special radiographic procedures, such as the techniques used by Clark, Miller-Winter and Donovan [1,2].

The cone-beam computed tomography (CBCT) is a very useful tool in the assessment of impacted teeth and is being widely used instead of or in addition to conventional techniques. Its main advantages include: more detailed visualization of the region where surgery will take place, when compared with other conventional types of radiographs, and reduced patient exposure to radiation in comparison with helical computed tomography [3].

*Address correspondence to this author at the Rua José Eduardo dos Santos, 147, Garibaldi, Salvador, Bahia, Brazil. CEP 41940-455. Centro Integrado de Saúde Fernando Filgueiras, Sala 313; Tel: (55) (71) 3018 8813;

Fax: (55) (71) 3345 1959; E-mail: allexmorelli@ hotmail.com
With CBCT, the impacted tooth can be seen in multiplanar views (Multiplanar Reconstruction - MPR). This makes it possible to obtain the precise location of the tooth and to establish the relations between it and adjacent structures. [1, 4]. Quereshy et al. (2008) recommend the use of CBCT in the identification, planning and even assessment of surgical complications in the treatment of impacted teeth [5].

\section{CASE REPORT}

A 29-year-old patient, seen in a private office, complained of pain in the left maxillary region being unresponsive to painkillers. The only abnormality detected in physical examination of the above-mentioned region was the lack of the maxillary second premolar. There were also some restorations. All teeth responded positively to pulp vitality test.

A close-up of the panoramic radiograph (Fig. 1) showed that the maxillary left second premolar was impacted and in an inverted position, and its apical third was dilacerated towards the distal direction, and there was an opaque area in the maxillary sinus related to the impacted premolar apex. In addition, uneruption of the left upper third permanent molar, over-eruption of the left upper second permanent molar, partial anodontia (absence of the left inferior second permanent premolar and the right inferior second permanent premolar) and retention of the left inferior second deciduous molar and the right inferior second deciduous molar were observed.

For better clarification of the location of the teeth, CBCT imaging was requested. The saggital view (Fig. 2) showed root dilaceration more clearly, and the mucosal thickening in the left maxillary sinus explained the opacification observed in the panoramic radiograph. Vestibular surgical access was recommended because the tooth was centrally positioned. 


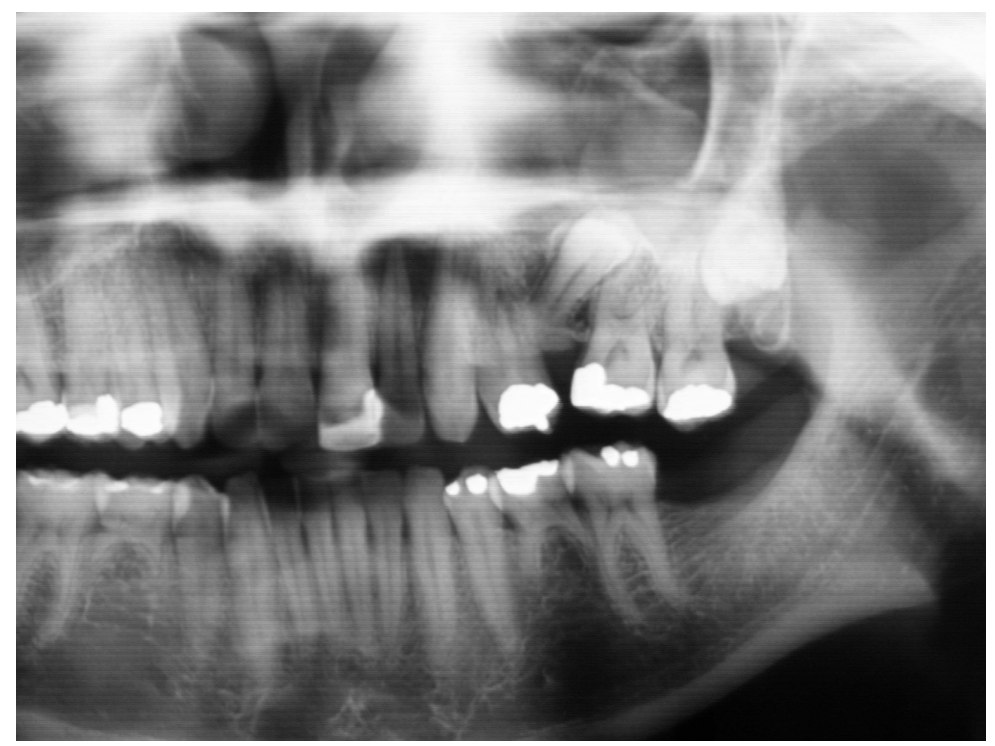

Fig. (1). Panoramic radiograph showing the maxillary left second premolar that is impacted and in an inverted position. The precise relation of the tooth with the maxillary sinus cannot be identified.

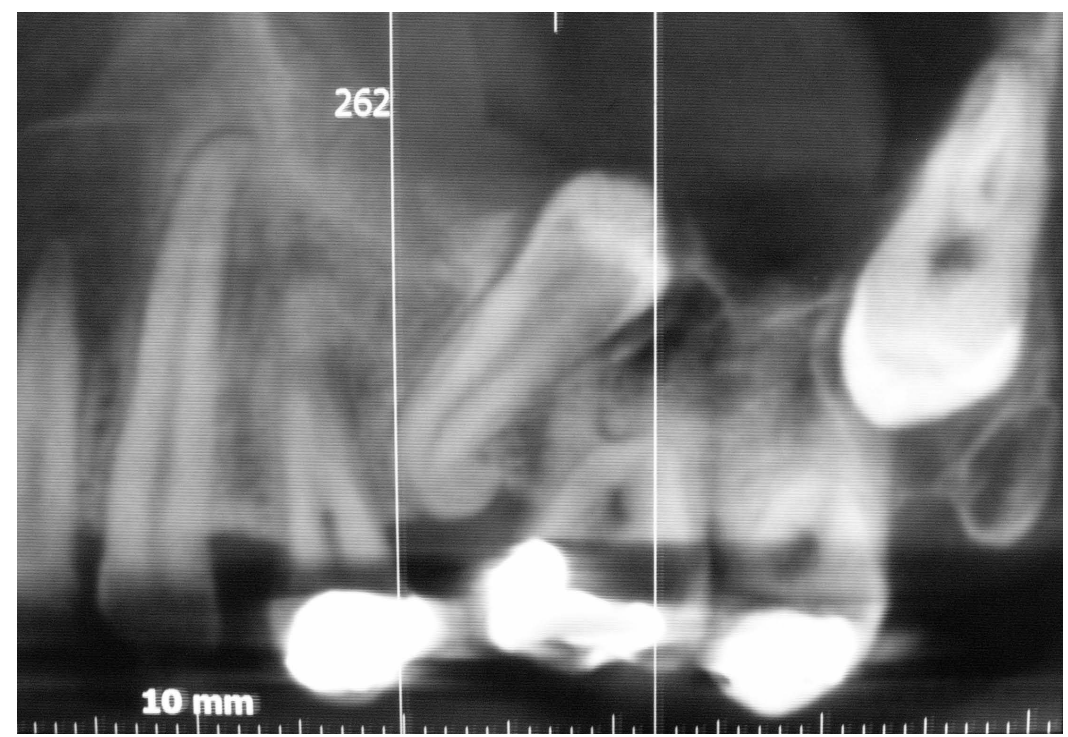

Fig. (2). Saggital view showing the relation of the tooth to the maxillary sinus, root dilaceration and mucosal thickening in the maxillary sinus.

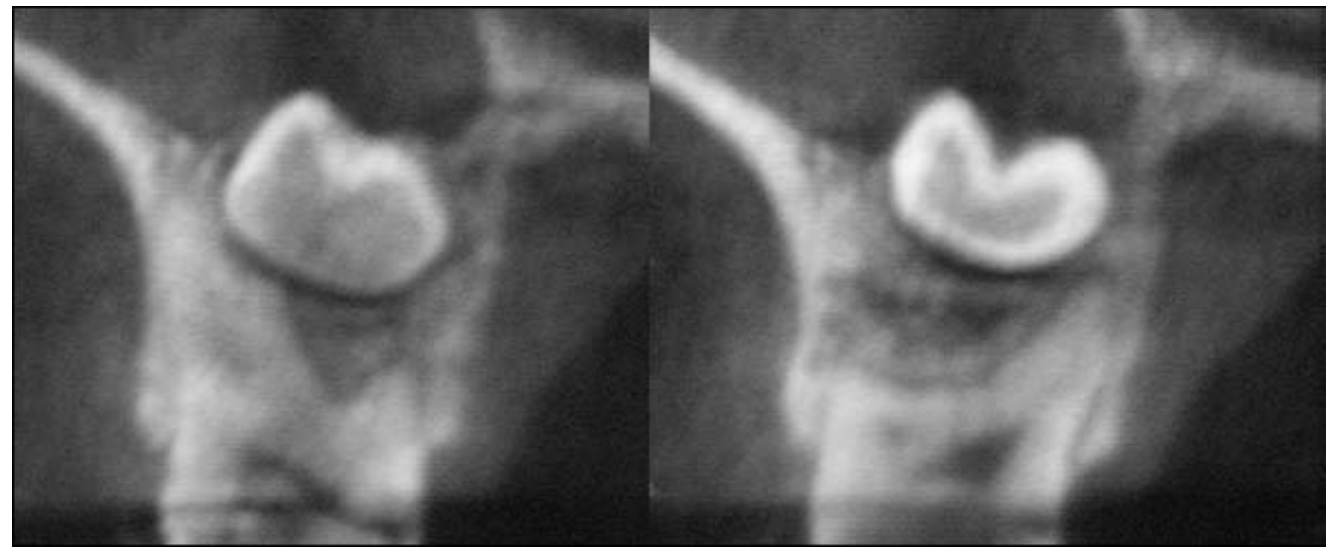

Fig. (3). CBCT cross-sectional views showing the tooth crown protruding into the maxillary sinus.

Analysis of the cross-sectional view (Fig. 3) showed the tooth crown protruding into the maxillary sinus. Patient management under local anesthesia, access to the maxillary sinus sinus was obtained by raising a mucoperiosteal flap and performing osteotomy of the lateral maxillary wall (Fig. 4). Subsequently, sectioning of the apical third of the impacted 


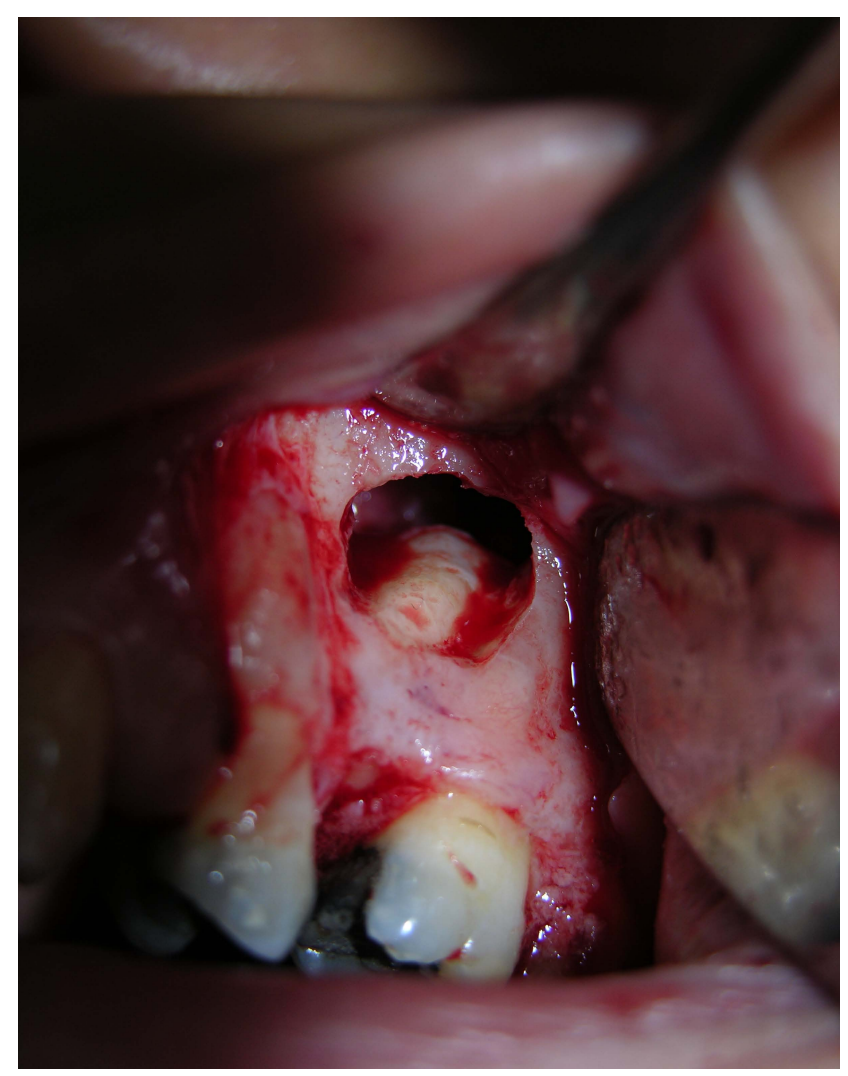

Fig. (4). Surgical access to the maxillary sinus for performing exodontia with preservation of the alveolar bone.

premolar was performed, eliminating the dilaceration, which made it possible to extract the tooth via the maxillary antrum. All the inflammation and remains of the pericoronal follicle were curetted from the maxillary sinus.

The relationship of the impacted tooth to the maxillary sinus could not be clearly visualized in the panoramic imaging. Only with CBCT imaging was it possible to observe that the tooth crown protruded into the maxillary sinus. Thus, a more conservative surgical access was selected, which provided greater bone preservation and reduced procedure time. The alveolar ridge remained intact, except in the region of sectioning of the impacted premolar.

The patient recovered well after 10 days, with complete remission of pain and infection after the administration of antibiotics in the first 10 postoperative days $(500 \mathrm{mg}$ amoxicillin three times a day) and anti-inflammatory drug (nimesulide $100 \mathrm{mg}$, twice a day for four days). The patient was subsequently referred to an orthodontist to regain space in the tooth arch, and the placement of an osteointegrated implant was planned for the purpose of rehabilitation.

\section{DISCUSSION}

The gathering of diagnostic information is essential in decision-making with regard to surgical procedures. Therefore, selection of the appropriate imaging examination is important in surgical planning, and produces more predictable results [6].

CBCT can provide more information than is obtained from conventional radiographs. [7], reporting a case of an ectopic third molar in the subcondylar region demonstrated the importance of CBCT in surgical planning. It was possible to use the intra-oral approach only due to information obtained with CBCT imaging, enabling a conservative and less traumatic approach.

CBCT plays a relevant role in the treatment of impacted teeth. In their analysis of surgical accesses to impacted teeth in different imaging modalities, Tantanapomkul W, demonstrated that CBCT is more effective than other 2D methods (greater sensitivity and specificity) [8].

Only after obtaining a CBCT image, were able to detect the protrusion of the tooth crown of a maxillary third molar into the maxillary sinus [9]. The relationship of the root of this tooth to the maxillary sinus could not be observed in conventional radiographs.

Sverzut et al. (2009) demonstrated the importance of CBCT in locating a maxillary molar accidentally dislocated into the infratemporal fossa [10]. According to the authors, unlike the conventional radiographs, CBCT allowed the accurate location of the tooth.

According to Lima et al. (2009), the main advantage of CBCT is that it allows the detailed visualization of teeth and bone [1]. We agree with the authors when they affirm that only through the accurate visualization of the impacted tooth provided by 3D images, can the surgeon obtain a more convenient and accurate access to the surgical field. This will preserve alveolar bone structure.

The surgery in the case reported here was planned with the use of CBCT imaging. Only after the generation of CBCT imaging was the precise location of the impacted tooth obtained, and more importantly, its relationship to the maxillary sinus was identified. This made it possible to perform exodontia causing minimal trauma to the alveolar bone, which is strategically important in restorations using dental implants. Munir and Siqueira (2009) stress the widely disseminated current concern about preservation of bone tissue after exodontias [11]. They feel extra care should be taken when rehabilitation with implants is considered.

The importance of CBCT in planning the surgical extraction of impacted teeth is undeniable. The reported case shows that a more detailed examination may assist surgical strategies, and provide valuable biological benefits. One of the main challenges in dentistry, especially in implant dentistry, is the reconstruction of bone defects. The unnecessary loss of the alveolar ridge has been widely condemned, because the reversion of this condition can be very expensive. Therefore, every effort must be made to ensure the use of surgical approaches that are as conservative as possible, in order to preserve the bone tissue.

\section{ACKNOWLEDGEMENT}

None declared.

\section{CONFLICT OF INTEREST}

None declared.

\section{REFERENCES}

[1] Lima ILA, Silva AIV, de Oliveira FJ, et al. Radiografias convencionais E tomografia computadorizada cone-bean para localização 
de dentes inclusos: relato de caso. Arq Bras Odontol 2009; 52: 5864.

[2] Haney E, Gansky SA, Lee JS, et al. Comparative analysis of traditional radiographs and cone-beam computed tomography volumetric images in the diagnosis and treatment planning of maxillary impacted canines. Am J Orthod Dentofacial Orthop 2008; 137(5): 590-7.

[3] Costa CC, Moura-NC, Koubik ACGA, et al. Aplicações clínicas da tomografia computadorizada cone beam na endodontia. Rev Isnt Ciênc Saúde 2009; 27(3): 289-6.

[4] Liu DJ, Zhang WL, Zhang ZY, et al. Localization of impacted maxillary canines and observation of adjacent incisor resorption with cone-beam computed tomography. Oral Surg Oral Med Oral Pathol Oral Radiol Endod 2008; 105(1): 91-8.

[5] Quereshy FA, Savell TA, Palomo JM. Applications of cone beam computed tomography in the practice of oral and maxillofacial surgery. J Oral Maxillofac Surg 2008; 66: 791-6.

[6] Merrett SJ, Drage NA, Durning P. Cone beam computed tomography: a useful tool in orthodontic diagnosis and treatment planning. J Orthod 2009; 36: 202-10.
[7] Bortoluzzi MC, Manfro R. Treatment for ectopic third molar in the subcondylar region planned with cone beam computed tomography: a case report. J Oral Maxillofac Surg 2010; 68: 870-2.

[8] Tantanapomkul W. Comparative study of cone-beam computed tomography and conventional panoramic radiography in assessing the topographic relationship between the mandibular canal and impacted third molars. Oral Surg Oral Med Oral Pathol Oral Radiol Endod 2007; 103(2): 253-9.

[9] Nakagawa Y, Kobayashi K, Ishii H, et al. Preoperative application of limited cone beam computerized tomography as an assessment tool before minor oral surgery. Int Assoc Oral Maxillofac Surg 2002; 31: 322-7.

[10] Sverzut CE, Trivellato AE, Sverzut AT, et al. Removal of a maxillary third molar accidentally displaced into the infratemporal fossa via intraoral approach under local anesthesia: report of a case. J Oral Maxillofac Surg 2009; 67: 1316-20.

[11] Munir S, Siqueira JTT. Uso de barreira de polipropileno pós exodontia. relato de três casos clínicos. Rev Bras Implant 2009; 15(2): $12-5$.

Received: March 03, 2012

Revised: March 20, 2012

Accepted: March 20, 2012

(C) Mattos et al.; Licensee Bentham Open.

This is an open access article licensed under the terms of the Creative Commons Attribution Non-Commercial License (http://creativecommons.org/licenses/by-nc/3.0/) which permits unrestricted, non-commercial use, distribution and reproduction in any medium, provided the work is properly cited. 